
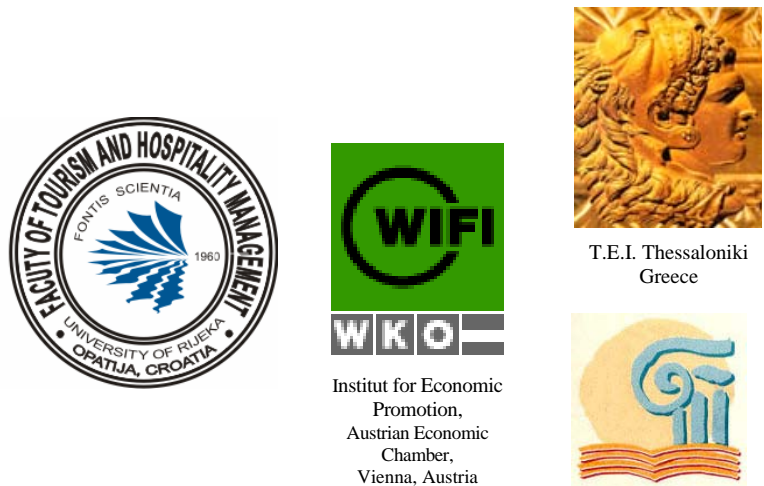

T.E.I. Thessaloniki

Greece

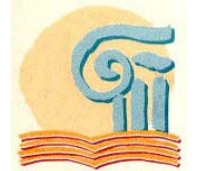

Department of Tourism Management
UDC 81'276:338.48:811.111'27

Original scientific paper Received: 04.03.2008

\title{
ENGLISH IN TOURISM: A SOCIOLINGUISTIC PERSPECTIVE
}

\author{
Renata Fox \\ University of Rijeka, Croatia ${ }^{1}$
}

Abstract: Tourism has become one of the central phenomena of a post-modern society greatly owing to its liaison with language. Especially prominent is the link between tourism and English language which, being the global lingua franca, not only monopolises all negotiations/transactions that take place in a tourist destination, but also functions as a creator of a destination's many realities, indeed as the very embodiment of processes in tourism. Over the past decade the multifunctionality of English in tourism has attracted considerable sociolinguistic research. This paper discusses the importance of merging sociolinguistics with the theory of tourism. The clear advantage of tourism scholars' acceptance of sociolinguistics as an accredited field of study lies not only in developing new understandings of language/discourse in tourism but also in an increased transdisciplinarity of two perceivedly distant fields of study: sociolinguistics and tourism.

Key words: English language, tourism, sociolinguistics, modes of knowledge, transdisciplinarity.

\section{INTRODUCTION}

The variety of ways in which English language relates to tourism has attracted much attention. Within a range of fields of study--for example, theory of tourism, destination marketing/management/branding, hospitality, advertising, sociology of tourism--English in tourism has been highlighted as a factor of the process of 'language brokerage' (Cohen and Cooper 1986), as a means of promoting a global lifestyle

${ }^{1}$ Renata Fox, Ph.D., Associate Professor, Faculty of Tourism and Hospitality Management, University of Rijeka, Croatia. 
Tourism and Hospitality Management, Vol. 14, No. 1, pp. 13-22, 2008

R. Fox: ENGLISH IN TOURISM: A SOCIOLINGUISTIC PERSPECTIVE

(Thurlow and Jaworski 2003), as a key element of tourist destination branding (Morgan, Pritchard and Pride /eds./ 2002), as enabling individuals to experience their identity through tourism (Palmer 2005), as shaping a tourist destination (Cappelli 2006), as a key factor of tourists' perceptions (Phipps 2006), as a carrier of a destination's 'sovereign subjectivity' (Bryce 2007) and, not least, as crucial for the new theorising of tourism (Ateljevic, Pritchard and Morgan /eds./ 2007).

What has become prominent over the past decade is a powerful sociolinguistic turn (e.g., Dann 1996; Jaworski and Pritchard (eds.) 2005; Jaworski, Thurlow, YlanneMcEwen and Lawson 2007) in researching language and tourism. The new angle has redirected the research into English language in tourism towards explicit links between theoretical and empirical perspectives on the tourist experience, identity, performance and authenticity within the frame of sociolinguistics and discourse analysis. It is the aim of this paper to discuss the need for and potentials of sociolinguistics as a field of study that can be useful to both tourism scholars and tourism managers. The paper opens with general comments on the systemic character of a destination's public communication. Follows an elaboration of the communicative purposes of a destination's communicative events. Section four briefly addresses the issue of a destination's communicative event as an artefact. In the next two sections social phenomena of the promotionalisation of public discourse and isomorphic pressures are expounded. Section seven offers a discussion of the value of sociolinguistic knowledge for a tourism researcher. An overview of previous sociolinguistic research into language in tourism along with a comment on what remains to be done is given in section eight. The paper concludes by appraising the key strategic advantages of including sociolinguistics into the research of language/discourse in tourism.

\section{A SET OF COMMUNICATIVE EVENTS}

A tourist destination's public discourse, for its importance to be fully appreciated, has to be viewed as a system: a theoretical construct which is hierarchical, and functional (Fox 2006b). This system consists of a number of communicative events (for example, a media advertisement, a destination brochure/video, a guidebook, a destination's webpage), involving an event itself, the event's participants (employees in tourism, visitors to a destination), and the environment of the event's production and reception (traditional printed/visual media, internet). Any such communicative event is strategic (fundamental to the destination's identity), preplanned (created within a destination's formal communication network), and recorded (tangible in verbal and/or non-verbal form).

It should, however, be mentioned that a significant part of a tourist destination's presence in the public space is materialised through travel articles and travelogues which are written by travel authors who are either independent or appointed by specialised/general journals or publishers. Unlike destination-generated tourist materials whose main task is to persuade the consumer that a particular resort is superior to other similar resorts, and whose evaluation of a destination cannot be anything but positive, travel articles and travelogues can contain both positive and negative evaluations. This paper is concerned only with destination-generated tourist 
Tourism and Hospitality Management, Vol. 14, No. 1, pp. 13-22, 2008

R. Fox: ENGLISH IN TOURISM: A SOCIOLINGUISTIC PERSPECTIVE

materials. Produced with the intention of creating the best possible public image of a destination, and fully controlled by a destination, destination-generated tourist materials are, in fact, a perfect evidence of a tourist destination management's ideas about the function, scope and power of a destination's public discourse.

\section{COMMUNICATIVE PURPOSES}

A tourist destination's communicative event, as any other communicative event, is driven by two communicative purposes, general and specific, which determine the schematic structure of the event and constrain choice of content and style (Fox and Fox 2004). Whereas the general communicative purpose relates to the objective of the communicative event and, as such, is common to all communicative events of a tourist destination, the specific communicative purpose relates to the event's content and, as such, varies from event to event. A class of tourist destination communicative events sharing the same specific communicative purpose constitutes a destination genre: a category which redefines a destination's communicative event at a higher level of abstraction and relates that event to other communicative events in the same class (Fox 2006b).

Let us, for example, take a destination brochure. The general communicative purpose common to all such brochures is the institutionalization of the destination's ideology. The specific communicative purpose will vary from one destination brochure to another: one brochure might emphasise natural beauties, the other might go for historical heritage, the third will focus on gastronomy, etc. When creating a new destination brochure, a tourist destination is invariably focused on two chief aims: informing and promoting (e.g., Middleton 1990; Morgan and Pritchard 2000). Both of these aims will be realised within a brochure's specific communicative purpose which, as previously noted, is related to content. In other words, it is through its content that a destination brochure aspires to accommodate two angles: the angle of (prospective) customers with their need for facts about a destination and the angle of brochure producers (usually a destination's tourist authority) with their intention to promote and motivate. From both the informing and the promoting angle, certain facts will be considered absolutely indispensable. From the informing angle these will be, for example, the details about tourist infrastructure (opening times, approximate prices), a map of the destination showing tourist facilities and attractions, the info about the nearest railway station, coach terminal, airport, etc., and, finally, reference to other information material (calendar of events, map of trails, special offers etc.). The promotional aspect of the brochure, on the other hand, will be realised through targeted selection, purposeful organisation and effective combination of verbal and visual elements which will result in precise semiotic messages. In practice, of course, these two angles, informing and promoting, are indivisible: a particular selection of information can have a very specific promotional effect and, vice versa, each promotional strategy is based on a specific selection and organisation of facts (Fox and Fox 1998).

In creating a communicative event which will benefit both the consumer and the destination, the event creator is bound to follow certain rules. In the case of a 
destination brochure, for example, these rules generally refer to three levels of the event: textual, syntactical, and lexical. Text, for example, is recommended to be clear, precise, correct, and, above all, easy to follow. Needles to say, the clarity and logic of text very much depend on the copywriter's command of syntax. Also, some believe that the use of active voice is preferable to passive: whereas active implies involvement and activity, passive voice, apparently, can suggest distancing from the tourist as a person (Tarlow 1996). The importance of lexical items in the language of tourism has been dealt with by a number of authors (e.g., Cohen 1985; MacCannell 1989; Dann 1996; Fox 1999, 2004a, 2006b). Key words, selected mainly for their stimulating effect, are typically adjectives (for example, superb, great, lovely) and nouns (for example, adventure, dream, discovery). Their function is not only refer to the attributes of the destination but also to communicate promises which both connect to the existing desires of tourists and arouse new ones.

So far research into destination-generated tourist materials has amply covered a specific communicative purpose realised through material's informing and motivating functions (for the link between the information sources and the destination selection cf. for example, Woodside, Crouch, Mazanec, Oppermann, Sakai 2000; Sönmez and Sirakaya 2002; Sirakaya and Woodside 2005; for the link between promotional function and destination choice, for example, Court and Lupton, 1997, Sirakaya, Sönmez and Choi 2001; also Morgan and Pritchard 2000; Morgan, Pritchard and Pride /eds./ 2002). Although promotional materials are generally taken to be vital in the destination selection process in the sense that customers compare material and that such comparison can significantly affect their choice of destination, some authors (e.g., Morgan and Pritchard 2000) claim that there is little empirical evidence to this. It seems that the promotional materials are used more to confirm than to identify holiday choices.

What both descriptive and prescriptive writings on destination-generated tourist materials somehow tend to take for granted and therefore oversee, is the general communicative purpose. Although there exists a considerable research into the identity of a tourist destination (e.g., Morgan and Pritchard 1998; Robinson /ed./ 2000; Walton /ed./ 2005; Burns and Novelli /eds./ 2006), the understanding of that identity tends to be linked to the contents rather than objectives of a destination's public discourse. Only research that is systematically focused on the goals of a destination's public discourse can trace the development of a destination's identity--a collection of ideas, concepts, meanings, events... on which the functioning of a tourist destination is founded--starting with commodification and spectacularisation, leading to institutionalization and legitimization, and, only then, to the promotionalisation of that identity. A focus on a destination's public discourse goal rather than content enables the researcher to get to a tourist destination's ideology: a cognitive system within a destination that sets priorities among the ideas, concepts, meanings, events... that create a destination's identity and legitimises some of those ideas, concepts, meanings, events... as more relevant to the benefit of a destination. 
Tourism and Hospitality Management, Vol. 14, No. 1, pp. 13-22, 2008

R. Fox: ENGLISH IN TOURISM: A SOCIOLINGUISTIC PERSPECTIVE

\section{ARTEFACTS}

A product of a specific set of living conditions of a destination, embodying a practical sense, and assuming material form, tourist destination communicative events function as artefacts. They are profoundly social in the sense that they both reflect and engage social context which at the same time is created by a destination, represents a destination and shapes its behaviour. A tourist destination's communicative events acting as artefacts position the destination and its actions socially thus embodying a practical sense, which is a part of a destination's habitus: a set of 'mental or cognitive structures' through which destinations deals with the rest of society (cf. Bourdieu 1989, 1990). As a product of socialities of a tourist destination, a destination's habitus defines both a destination's social practices and tourists' perception of those practices. As an inevitable part of the destination's habitus, a destination's artefacts maintain and reproduce the circumstances that made these social practices possible. Two sets of social circumstances clearly detectable in the process of producing promotional materials are promotionalisation of public discourse and isomorphic pressures.

\section{PROMOTIONALISATION OF PUBLIC DISCOURSE}

A part of a destination's public communication, tourist destination public communicative events are by definition subject to the 'generalization' of promotion as a communicative function, which is probably the most obvious discourse-related manifestation of contemporary consumer culture (cf. Wernick 1991). The life in postmodern society which views consumption as the most desirable of all modes of behaviour and a commodity in itself, is highly destandardised: the range of acceptable behaviours has increased, and there is no longer a 'regular' life pattern (Buchmann 1989). Tourists, as all other consumers, are, in reality, 'hedonists and dreamers' torn between the perfections of their dreams and the imperfections of reality, which gives rise to their 'continual longing' and 'inexhaustability of wants' (Campbell 1995: 95) and enables them to 'experience in reality the pleasurable dramas which they have already enjoyed in imagination' (p. 89-90). Believing themselves able to direct their own lives, tourists, as indeed other consumers, are becoming increasingly unpredictable. To control tourists and regulate their behaviour, tourist destinations continually intensify their public communication while at the same time emphasizing its promotional function. This is best seen in a destinations' reliance on the discourse of advertising which not only plays on the tourists' needs and reasons for consumption, but also endeavours to appeal to tourists as consumers, to the ideology of consumerism, and to social apparatuses of controlling tourists as consumers (Fox 2006b).

\section{ISOMORPHIC PRESSURES}

A second important social mechanism affecting the creation of a destination's public discourse will be isomorphic pressures: 'a constraining process that forces one unit in a population to resemble other units that face the same set of environmental conditions' (DiMaggio and Powell 1983: 143). The concept of institutional isomorphism has been developed to account for the tendency of organisations to become more and more similar 
to one another, as to cope within an increasingly rationalised society. According to DiMaggio and Powell, it is the processes of isomorphism which result from three types of social pressure--issues of legitimacy, uncertainty, professionalisation--that account for much of the life of organisation as well as the relationship between the organisation and society.

There is a definite similarity between corporations and tourist destinations in the sense that tourist destinations, when communicating to the rest of society, do not start from scratch neglecting all that has been done before. Neither do they list relevant theories, for example, communication and language/discourse theories, to draw from them when formulating their public discourses. Rather, just like corporations, tourist destinations, under the pressure of the need for legitimacy, uncertainty, and increasing professionalisation, imitate other (similar, more famous and/or more successful) destinations and learn from each other.

The issues of political influence and legitimacy prompt coercive isomorphism which will be manifested in a destination's endeavour to satisfy social expectations of its habitus: the need for destination-generated tourist materials to be truthful, informative and motivating.

Uncertainty of the social environment (due to fierce competition on the global tourist market, the life of a tourist destination is invariably full of uncertainty) encourages mimetic isomorphism. 'Modelling' the examples of others can helps tourist destinations generate useful solutions at little expense. Indeed, when comparing destination brochures, one somehow has the impression that the key words and phrases launched in the public discourse of leading tourist destinations, for example, New York, Monte Carlo or Seychelles, do not take long to ripple through other, more mass market destinations' discourses. Supplying hard evidence for this is, however, not simple. In comparison to coercive isomorphism, mimetic isomorphism is known to be more subtle, less visible, perhaps easier to detect but almost impossible to prove. Also, neither the lender nor the borrower may be fully aware of the goings on. While leading tourist destinations do not exactly desire to be copied, they are aware of the inevitability of their communicational practices being treated as exemplary and therefore emulated by others. Borrowers, on the other hand, start by imitating a specific communicative event (e.g. a destination brochure) of another (more competitive) tourist destination. However, borrowers' awareness of the general importance of originality in public communication, will prompt them to, sometimes unexpectedly or unwittingly, create a communicative event which will turn out characteristically theirs. Both coercive and mimetic isomorphism are constrained by social authority which is exerted by social powers (in case of a tourist destination these would be a destination's social environment and stakeholders) and which assures discourse production within the frame of genre-defining rules.

Finally, a product of professionalisation is normative isomorphism. As all other industries, tourism is subject to continually increasing professionalisation which is derived from two main sources: formal education and networking. Numerous schools and universities in the area of tourism and hospitality, along with professional associations, are responsible for creating norms which, to quote DiMaggio and Powell (1983: 152), result in the 'pools of almost interchangeable individuals who occupy similar positions 
Tourism and Hospitality Management, Vol. 14, No. 1, pp. 13-22, 2008

R. Fox: ENGLISH IN TOURISM: A SOCIOLINGUISTIC PERSPECTIVE

across a range of organisations' in tourism and hospitality industry and 'possess similarity of orientation and disposition that might override variations in tradition'.

\section{FROM IDEAS TO A THEORY}

What is needed here is a conceptual frame that will in a logical and parsimonious manner accommodate the social circumstances of a destination's public discourse (generalisation of promotion as a communicative function and isomorphic pressures) and the public discourse itself. While the daily practices of a tourist destination's public communication imply some set of abstract ideas that give meaning to and shape those practices, these ideas may not necessarily be a part of a destination management's declarative knowledge. Nevertheless, whenever a destination and its management are involved in a discoursal practice, more specifically, whenever they create a communicative event, they are inevitably acting on ideas. Put together, these ideas can provide the basis for a general theory of a destination's public communication (Fox 2004b, also cf. Fox and Fox 2004).

A comprehensive theory that can link a destination's use of language/discourse to the social constraints of that use while at the same time enabling both its critique and improvement, is offered in sociolinguistics: a field of study focused on the ways language functions in society, on the nature of relationships between language and society (its institutions), and on the role of individuals and groups in sociolinguistic phenomena. Since every act of communication is socially relevant (in the sense that it is both socially situated and socially situating), many linguists view all linguistics as, in fact, sociolinguistics. When Halliday wrote: 'the linguistic system is a sociolinguistic system' (1978: 72), he wished to make clear that researching language functions refers to both studying components of meanings in the language system (the potential) and studying social meanings of individual speech acts (the actual).

In the early 1970s sociolinguistics became established as a discipline. Since then it has been applied to areas such as language varieties, language and identity, language policy, media communication, educational issues. Today, sociolinguistics is truly interdisciplinary constituting a meeting ground for a variety of fields of study, such as, sociology, sociopsychology, ethnography, and cultural studies. In light of the variety of research traditions, aims and attitudes which meet in the field of sociolinguistics, three positions have been taken in relation to the issue of what constitutes sociolinguistic theory. First, sociolinguistic theory is considered to be a part of linguistic theory with the chief aim of improving an understanding of the social nature of language. Second, sociolinguistics is viewed as an accumulation of mini-theories (e.g., 'face' theory, 'accommodation' theory, 'network' theory). While leading sociolinguists (e.g., Coulmas /ed./ 1997, 2005; Coupland 1998; Hudson 1998) have suggested that sociolinguistics should aspire to an independent theory, the very diversity of social processes researched within sociolinguistics is a strong argument against sociolinguistics as a unified theory. Finally, sociolinguistics is treated as a social theory focusing on the social analysis of language. The linguistic turn in social sciences has rendered social analysis of language, and accordingly sociolinguistics, indispensable to social research. It is precisely the sociolinguistic theory that has the potential to advance social theory and thus provide the 
Tourism and Hospitality Management, Vol. 14, No. 1, pp. 13-22, 2008

R. Fox: ENGLISH IN TOURISM: A SOCIOLINGUISTIC PERSPECTIVE

best account of how 'people position themselves and their social worlds through language’ (Coupland 1998: 116).

\section{SOCIOLINGUISTIC RESEARCH INTO THE LANGUAGE OF TOURISM}

The first systematic sociolinguistic treatment of language and tourism was provided by Graham Dann in his seminal and by now classic The Language of Tourism: A Sociolinguistic Perspective (1996). Starting with the assumption that tourism has a discourse of its own, and that tourism, indeed, constitutes discourse, Dann offers a rich analysis of the many social functions of language in tourism: as an instrument of customers' active involvement (not only in the process of consumption but also in the process of co-creating language that induces them to consume), as a process of social control (by containing norms and values), and as a medium of socialization (employed by all stakeholders in development of their identities). Apart from creating a completely new understanding of language (also language techniques and language registers) in tourism, the book offers a fresh perspective on an extensive body of related research (within the fields of sociology, anthropology, semiotics, philosophy, communicational studies, and destination management).

Dann's book paved a path for further sociolinguistic explorations into language of tourism (e.g., Thurlow and Jaworski 2003; Jaworski and Pritchard /eds./ 2005; Cappelli 2006; Fox 2006b; Phipps 2006; Brice 2007; Jaworski, Thurlow, Ylanne-McEwen and Lawson 2007) generally focusing on the language as a creator of identities, power and social differences in the context of tourism.

The next step, it seems, should be the adoption of sociolinguistics as an accredited theory (or a set of theories) by the scholars in tourism, destination management/marketing/branding, hospitality, etc. Bringing sociolinguistics into dialogue with the theory of tourism would constitute an important contribution to the inherent transdisciplinarity of tourism as a field of study which, precisely because of its tendency to socialize with other fields of study, has been referred to as 'undisciplined' (Tribe 1997). Growth of transdisciplinarity in any field of study, tourism too, means an acceleration of the progress towards mode-2 knowledge: a new type of knowledge which involves a variety of mechanisms of creating/communicating knowledge, participants from numerous disciplinary backgrounds, and a great diversity of sites in which knowledge is produced (Gibbons et al. 2005; Fox2006a, 2007). Unlike traditional forms of knowledge, usually referred to as mode-1 knowledge, which are disciplinary, homogenous, hierarchical and dictated by the interests of academic communities, mode-2 knowledge production is transdisciplinary, heterogenous, heterarchical and transient. In consequence, it is more socially accountable and reflexive. Therefore, adoption of sociolinguistics as supportive to the theory of tourism will constitute a decisive move towards a new paradigm of tourism research which will lead to the generation of new types of knowledge and, in turn, enable new insights into the increasingly complex relationship between language and tourism. 


\section{DISCUSSION}

Whether seen as complementary to linguistic theory, as a collection of minitheories, as an independent social theory, or as a combination of all three, sociolinguistics can provide a researcher with an objective insight into the language-tourism relationship. More precisely, it offers a theoretical frame for the systemic description and critical analysis of the use of language in tourism from a variety of perspectives.

Linking language to society in a systemic way, sociolinguistics enables description/analysis of a destination's public discourse both as an instrument of positioning/selling a destination on the tourist market and as a creator of a tourist destination. In other words, a sociolinguistic understanding of a tourist destination's public discourse enables researchers, and practising managers too, to recognise a tourist destination's public discourse as much more than just feeding information cum promotion to the consumer.

A tourist destination language/discourse researchers' awareness of the indispensability of sociolinguistics to a systemic understanding of a destination's public discourse will gradually make sociolinguistics an integral part of metatheorising tourism: a process aimed both at an improved understanding of the existing theories within tourism as a field of study, and at further development of the theory of tourism itself, that is, at creating perspectives that overarch the existing theory by involving a seemingly distant field of study: sociolinguistics.

\section{REFERENCES}

Ateljevic, I., Pritchard, A. and Morgan, N. (eds.) The Critical Turn in Tourism Studies: Innovative Research Methodologies. Amsterdam: Elsevier, 2007.

Beaugrande, R., de, New Foundations for a Science of Text and Discourse: Cognition, Communication, and the Freedom of Access to Knowledge and Society. Norwood, NJ: Ablex, 1997.

Bourdieu, P., "Social space and symbolic power”. Sociological Theory, 7, 14-25, 1989.

Bourdieu, P., The Logic of Practice. Cambridge, MA: Harvard University Press, 1990.

Bryce, D., "Repackaging Orientalism: Discourses on Egypt and Turkey in British outbound tourism”. Tourist Studies, 7/2, 2007, 165-191.

Buchmann, M., The Script of Life in Modern Society: Entry into Adulthood in a Changing World. Chicago: University of Chicago Press., 1990.

Burns, P. M. and Novelli, M. (eds.) Tourism and Social Identities. Elsevier Science, 2006.

Campbell, C., The Romantic Ethic and the Spirit of Modern Consumerism. Oxford: Blackwell, 1995.

Cappelli, G., Sun, Sand, Sex and the Unspoilt Countryside: How the English Language Makes Tourists out of Readers. Pari: Pari Publishing, 2006.

Coupland, N., "What is a sociolinguistic theory?” Journal of Sociolinguistics, 2/1, 110-117, 1998.

Coulmas, F. (ed.) The Handbook of Sociolinguistics. Oxford: Blackwell, 1997.

Coulmas, F., Sociolinguistics: The Study of Speakers' Choices. Cambridge: CUP, 2005.

Cohen, E., "The tourist guide: The origins, structure, and dynamics of role”. Annals of Tourism Research, 12, 5-29, 1985.

Cohen, E. and Cooper, R.L., “Language and Tourism”. Annals of Tourism Research, 13/4, 533-563, 1985.

Court, B. and Lupton, R., "Customer portfolio development: Modeling destination adopters, inactives and rejecters”. Journal of Travel Research, 36/1, 35-43, 1997.

Dann, G. M. S., The Language of Tourism: A Sociolinguistic Perspective. CAB International, Wallingford, 1996.

DiMaggio, P. J., and Powell, W. W., “The iron cage revisited: Institutional isomorphism and collective rationality in organizational fields”. American Sociological Review, 48, 1983 
Tourism and Hospitality Management, Vol. 14, No. 1, pp. 13-22, 2008

R. Fox: ENGLISH IN TOURISM: A SOCIOLINGUISTIC PERSPECTIVE

Fox, R., “Jezik turizma: retorika kvalitete”. In Badurina, L., Ivanetic, N., Pritchard, B., Stolac, D. (eds.), Teorija i mogucnosti primjene pragmalingvistike. Zagreb-Rijeka: Croatian Applied Linguistics Society, 1999, 225-232.

Fox, R., "Gastrospeak: Towards gastronomic identity of Croatian tourism”. Proceedings Strategic Partnerships for the Development of Tourist Destination of the international conference Days of Turistica, held in Portoroz, Slovenia, 18-19 March 2004, 2004a.

Fox, R., "Sociolinguistics: The path towards professional literacy”. In Tourism and Hospitality Industry 2004. Proceedings of the international conference New Trends in Tourism and Hospitality Management, held in Opatija, 14-16 April 2004., 2004b.

Fox, R., "Participating in the transdisciplinary project: Applying corpus linguistics to corporate Identity". In B. Lewandowska-Tomaszczyk (ed.) PALC 2005: Practical Applications in Language Corpora. Frankfurt am Main: Peter Lang, 2006a.

Fox, R., "Reinventing the gastronomic identity of Croatian tourist destinations". International Journal of Hospitality Management, 26/3, 2006b, 546-559.

Fox, R., "Linguistics: towards metatheorising organisational discourse”. Proceedings of Critical Management Studies Conference, stream Management and Philology: Perspective on Languages, held in Manchester, 11-13 July 2007, University of Manchester, 2007.

Fox, R., Fox, J., “Go Global - Nurture Local”. In Nahrstedt, W., Pancic Kombol, T. (eds.), Leisure, Culture and Tourism in Europe: the Challenge for Reconstruction and Modernisation in Communities. Institut für Freizeitwissenschaft und Kulturarbeit, Bielefeld, 1998.

Fox, R., Fox, J., Organizational Discourse: A Language-Ideology-Power Perspective. Praeger, Westport, 2004.

Gibbons, M., Limoges, C., Nowotny, H., Schwartzman, S., Scott, P. and Trow, M., The New Production of Knowledge: The Dynamics of Science and Research in Contemporary Societies. London: Sage Publications, 2005.

Halliday, M. A. K., Language as Social Semiotic. London: Edward Arnold, 1978.

Hudson, R. A., Sociolinguistics, 2nd ed. Cambridge: CUP, 1998.

Jaworski, A. and Pritchard, A. (eds.) Discourse, Communication and Tourism. Clevedon: Channel View Publications, 2005.

Jaworski, A., Thurlow, C., Ylanne-McEwen, V. and Lawson, S. Language, Tourism and Globalisation: The Sociolinguistics of Fleeting Relationships. London: Routledge, 2007.

MacCannell, D. The Tourist: A new theory of the leisure class. New York: Schocken Books, 1989.

Middleton, V. T. C., Marketing in Travel and Tourism. Oxford: Heinemann Professional Publishing Ltd., 1990.

Morgan, N., Pritchard, A., Tourism, Promotion and Power: Creating Images, Creating Identities. London: John Wiley and Sons Ltd., 1998.

Morgan, N. and Pritchard, A., Advertising in Tourism and Leisure. Oxford: Butterworth-Heinemann, 2000.

Morgan, N., Pritchard, A. and Pride, R. (eds.) Destination Branding: Creating the Unique Destination Proposition. Oxford: Butterworth-Heinemann, 2002.

Palmer, C., “An ethnography of Englishness: Experiencing identity through tourism”. Annals of Tourism Research, 32/1, 2005, 7-27.

Phipps, A. M., Learning the Arts of Linguistic Survival: Languaging, Tourism, Life. Clevedon: Channel View Publications, 2006.

Robinson, M. (ed.) Expressions of Culture, Identity and Meaning in Tourism. Business Education Publishers Ltd., 2000.

Sirakaya, E., Sönmez, S. and Choi, H., "Do destination images really matter: Predicting destination Choices of student travellers”. Journal of Vacation Marketing, 7, 125-142, 2001.

Sirakaya, E. and Woodside, A., "Building and testing theories of decision making by travellers”. Tourism Management, 26, 815-832, 2005.

Sönmez, S. and Sirakaya, E., “A distorted destination image: The case of Turkey”. Journal of Travel Research, 41, 185-196, 2005.

Tarlow, P., “A Tourism Study for the Communities of Canyon Lake”. Tourism and More Consulting Services, 1996.

Thurlow, C. and Jaworski, A., “Communicating a global reach: Inflight magazines as a globalizing genre in tourism”. Journal of Sociolinguistics, 7/4, 579-606.

Tribe, J., “The indiscipline of tourism”. Annals of Tourism Research, 24/3, 638-657, 1997.

Walton, J. K. (ed.) Histories of Tourism: Representation, Identity and Conflict. Channel View Publications, 2005.

Wernick, A., Promotional Culture. London: Sage, 1991.

Woodside, A., Crouch, G., Mazanec, J., Oppermann, M. and Sakai, M., Consumer Psychology of Tourism Hospitality and Leisure. New York: CABI, 2000. 